\title{
VALERIANA JATAMANSI: AN ETHNOBOTANICAL REVIEW
}

\author{
AFROZ PATAN*, ALEKHYA K, VIJEY AANANDHI M, THARAGESH K, ANISH A
}

Department of Pharmaceutical Chemistry and Analysis, School of Pharmaceutical Sciences, Vels Institute of Sciences, Technology and Advanced Studies, Pallavaram, Chennai, Tamil Nadu, India. Email: afroz.sps@velsuniv.ac.in

Received: 10 October 2018, Revised and Accepted: 11 December 2018

ABSTRACT

Objective: The main objective of review is an effort to give detailed information on Valeriana jatamansi and its multiple medicinal properties.

Methods: As per the literature, the plant V. jatamansi is a perennial herb and found at subtemperate Himalayan regions of the Kumaon and Garhwal. The plant most popularly known as "Valerian." The plant belongs to the family Valerianaceae. The roots and rhizomes of the plants are traditionally used to treat ulcers, jaundice, dry cough, seminal weakness, skin diseases, leprosy, and for sleep enhancement due to the presence of a variety of different chemical constituents such as sesquiterpenes, coumarins, iridoids, lignanoids, alkaloids, and flavonoids. From literature, the reported methods performed for different pharmacological activities have been thoroughly discussed and complied.

Results: Most of the studies compiled from literature shown that $V$. jatamansi possess antimicrobial, antioxidant, anti-inflammatory, cytotoxic, anxiolytic, and neuroprotective activities.

Conclusion: The review reveals that continuous research on this plant is needed to know the exact molecular mechanism and further elaborative studies can lead to develop safe therapeutic use in modern medicine.

Keywords: Valeriana jatamansi, Valpotriate, Iridoids, Antioxidant, Anxiolytic activity.

(C) 2018 The Authors. Published by Innovare Academic Sciences Pvt Ltd. This is an open access article under the CC BY license (http://creativecommons. org/licenses/by/4. 0/) DOI: http://dx.doi.org/10.22159/ajpcr.2018.v11s4.31706

\section{INTRODUCTION}

The genus Valeriana belonging to the family Valerianaceae contains around 250 types of species which is distributed in all temperate regions of world. Among them in India, 16 species were found and out of them two subspecies of genus and five species in habitat at higher altitude range of Central Himalayas. The most popular name for this genus is "Valeriana." Valeriana jatamansi is commonly known as India Valerian, Muskbala, Sugandhbala (Hindi), and Tagar (Sanskrit) [1]. Indian Valeriana is a small herbaceous species distributed in tropical and temperate Himalaya up to an altitude of $3000 \mathrm{~m}$ between 1500 and $1800 \mathrm{~m}$ in Khasi and Jaintia hills; this has been used as an ingredient for herbal medicine in Indian system of medicine and substitutes for European Valeriana officinalis in India. Geographically, this species is available in different temperate regions and has diverse genetic and morphological features, which will affect the level of active constituents present [2]. V. jatamansi is a hairy dwarf and rhizomatous perennial herb growing up to $0.5 \mathrm{~m}$ with thick root stacks, covered with horizontal descending fibers and pubescent stem and radical leaves 1-3 cm in diameter. Flowers are white or tinged in pink color, fruits are crowned by persistent pappus calyx. This species is gynodioecious, the fruiting and flowering time occurs during the period of March-June and mode of proliferation is both sexual through seeds and abiogenetic through rhizome. $V$. jatamansi used in Ayurvedic and Unani system of medicine. The roots and rhizomes are used to treat insomnia, blood and circulatory disorders, asthma, dry cough, jaundice, seminal weakness, cardiac debility, and skin diseases. Its herbal oil is widely in use for making perfumery preparation and in insect repellent formulation. The V. jatamansi root contains $0.8 \%$ of essential oil and used in pharmaceutical industries and in hair preparations $[3,4]$.

Taxonomical classification

Kingdom: Viridiplantae

Class: Asterids

Order: Dipsacales
Family: Caprifoliaceae

Genus: Valeriana

Species: Jatamansi

Botanical name: V. jatamansi

\section{Synonyms}

Valeriana wallichii, Valeriana harmsii, Valeriana mairei, and Valeriana hygrobia.

\section{Vernacular names}

\begin{tabular}{ll}
\hline Language & Vernacular names \\
\hline Hindi & Balchhari, Mansi, Nihani, Smak, Sumaya, Tagar \\
Kannada & Jatale, Naati jatamaansi, Nandu batlu, Tagara \\
Malayalam & Takaram \\
Marathi & Thagar mool \\
Sanskrit & Jatamansi, Natah, Tagarah \\
Tamil & Shadamangie, Takaram \\
Telugu & Tagara \\
\hline
\end{tabular}

\section{Macroscopical characters of dried rhizome}

Dried rhizome is prolonged cylindrical in shape $2.5-12 \mathrm{~cm}$ long and $2-3.5 \mathrm{~cm}$ thick covered by groups of thick brownish rootlets bundles framing a network. The leaves are rose colored slightly pink or blue in sense.

- Color: Outer layer of rhizome is dark brown

- Inner layer is brown or yellow in color.

- Odor: Highly agreeable.

- Taste: Aromatic, bitter, and slightly camphoraceous.

- Size: 2.5-12 cm in length.

- Shape: Elongated and cylindrical.

Phytochemical constituents

$V$. jatamansi main active constituents are sesquiterpenes, coumarins, iridoids, liganoids, and sesquiterpenes include valerenic acid, and other derivatives include valeranone and valerenal. Moreover, liganoids 
include pinoresinol-4-o-d-glucoside and lignans 8'-hydro-xypinoresinol. Iridoids include valepotriates (valtrate, didrovaltrate, acevaltrate, and isovaleroxyhydroxyvaltrate) [6,7]. Alkaloids include chatinine, nordelporphine, norphoebine, thaliperphine, nantenine, phenanthrene, phoebine, dehydroaphine, valerine, valeriane, and oxoaporphine. Flavonoids in Valeriana mainly contain acacetin, hesperidin and methylapigenin, diosmetin, luteolin, quercetin, kaempferol, linarin, and luteolin. The other constituents are volatile oil, essential oil, sugar, bitter extractive matter, starch, gum, resin, and ketones $[8,9]$.

\section{Traditional uses}

In traditional system of medicine, the roots of plant are used to treat ulcer, convulsion, asthma, dry cough, jaundice, seminal weakness, cardiac debility and skin diseases, leprosy, general debility, and for sleep enhancement. Rhizomes and roots of $V$. jatamansi recommended to treat insomnia and blood, circulatory, and mental disorders. It stimulates central nervous system, acts as nerve tonic, and used in the treatment of anxiety and tremors. The plant was used as stimulant, hypotensive, and sedative. Its oil is used in perfumery preparation and insect repellent formulation [10].

\section{In vitro and in vivo studies \\ Antioxidant activity}

Methanolic, chloroform, and aqueous extracts of the dried roots of $V$. jatamansi were extracted and assessed for their polyphenol and flavonoid content. The antioxidant activity of the three solvent extracts of $V$. jatamansi roots and essential oil $(100 \mu \mathrm{g} / \mathrm{ml})$ and was assessed by 2,2-diphenyl-1-picrylhydrazylhydrate (DPPH) radical scavenging and ferrous chelation power assay [11]. Methanolic extract was found to be best when compared to that of essential oil [12]. In another study, the antioxidant activity and anti-inflammatory activity were studied by hydroalcoholic extracts of $V$. jatamansi using DPPH free radical scavenging and the percentage (\%) inhibition of proteins denaturation, respectively, using diclofenac sodium as the reference standard. A substantial decrease of various mediators of inflammation was seen due to the presence of bioactive compounds such as flavonoids, tannins, and polyphenols [13].

\section{Anti-inflammatory activity}

The aqueous and methanolic extracts from the rhizomes of $V$. jatamansi had shown to have significant anti-inflammatory activity. It decreases the inflammation in carrageenan-induced paw edema method in rats at dose levels of 100,150 , and $200 \mathrm{mg} / \mathrm{kg}$ in the presence of saline as control and reference drug was aspirin. Both the extracts significantly decreased due to inhibition of inflammatory mediators histamine, prostaglandin, and serotonin synthesis and exhibited anti-inflammatory effect at $200 \mathrm{mg} / \mathrm{kg}$ dose [14].

\section{Antibacterial activity}

The antibacterial activity was explored using hexane, chloroform, and methanolic extracts from rhizomes of V. jatamansi. Extendedspectrum B-lactamase produced by Escherichia coli, Enterobacter aerogenes, Klebsiella pneumoniae, and Hafnia alvei were isolated from urinary tract infection and subjected to double disc diffusion assay using three solvent extracts [15]. The inhibition was significant with hexane extract and can be given along with other antibiotics as new alternative treatment for urinary tract infection [16]. The methanolic, chloroform, and hexane extracts of $V$. jatamansi were evaluated for their antimicrobial effect against strains Staphylococcus aureus, Pseudomonas aeruginosa, Micrococcus luteus, E. coli, Salmonella ebony, Lactobacillus plantarum, and Staphylococcus epidermidis. Among them, the hydroalcoholic extracts with doses of $0.3-0.7 \mathrm{mg} / \mathrm{ml}$ shown better antibacterial activity against $S$. aureus, $P$. aeruginosa by cup plate method using Soyabean Casein Digest Agar medium, and chloramphenicol was standard antibiotic used at $1 \mathrm{mg} / \mathrm{ml}$. The antibacterial activity was due to the presence of valerenic acid an important chemical constituent which was isolated and characterized by thin-layer chromatography (TLC) and high-performance liquid chromatography (HPLC) by comparing the $R_{\mathrm{f}}$ and $\mathrm{R}_{\mathrm{t}}$ values using reference standard compound can be a better choice as a new antibacterial agent [17].

\section{Cytotoxic activity}

The underground parts, roots and rhizomes of all three Valeriana species V. jatamansi (V. wallichii), V. officinalis, and V. edulis Nutt, possess cytotoxic activity which has been proven by different studies. Fresh extracts and stored extract tinctures of three valerian species were explored for active principles baldrinals, valepotriates, and valerenic acid and cytotoxic activity was performed against COLO 320 a human colorectal and GLC (4) a human small cell lung cancer lines, by utilizing the microculture tetrazolium (MTT) assay [18]. A significant highest toxicity was observed by diene-type valepotriates (isovaltrate, acevaltrate, and valtrate) with IC50 (1-6 $\mu \mathrm{M})$, following continuous incubation. The data imply that isovaltral obtained from isovaltrate possess marked effects than its parent compound. The cytotoxic effect got reduced on storage as valepotriates decomposed, which shown weak cytotoxic effect [19].

An in vitro cytotoxic study was conducted on three valepotriate isomers, jataman valtrates $\mathrm{Z}_{1}, \mathrm{Z}_{2}$, and $\mathrm{Z}_{3}$, obtained from the air-dried whole plants of $V$. jatamansi (syn. V. wallichii). It was found that methanolic extracts exhibited moderate cytotoxicity using MTT assay against the metastatic prostate cancer (PC3M), lung adenocarcinoma (A549), hepatoma (Bel7402) cell lines, and colon cancer (HCT-8) [19]. The viability of cell lines was measured by observing absorbance at $570 \mathrm{~nm}$ using dimethyl sulfoxide as solvent and paclitaxel as positive control with IC50 values of $2.8-8.3 \mu \mathrm{M}[20]$.

Earlier studies reported that 10 new valepotriates, jataman valtrates (1-10), and one already reported compound, nardostachin (11), were extracted and isolated from the entire plants of V. jatamansi. 10 new valepotriates, jataman valtrates, compound's structures were determined by spectroscopic analysis and were subjected to access cytotoxic action against PC-3M cell lines, and SAR studies were performed and tested for all the above compounds and the in vitro cytotoxic data report proposed some particular functional groups were related to the cytotoxic activity against PC-3M cell lines. An unsaturated bond at $\mathrm{C}_{3}-\mathrm{C}_{4}$, the oxirane ring, and at $\mathrm{C}-10$ the chlorine atom presence in the valepotriates was highlighted as important structural features [21].

\section{Anxiolytic activity}

The anxiolytic properties of compound were explored from radix and rhizomes of Valeriana jatamansi in mice [22]. Male ICR mice were treated with compound V. jatamansi at dose levels of $1.2 \mathrm{~g} / \mathrm{kg}$, $2.4 \mathrm{~g} / \mathrm{kg}$, and $4.8 \mathrm{~g} / \mathrm{kg}$ and saline, diazepam $2 \mathrm{mg} / \mathrm{kg}$ given orally for 10 days and then examined using techniques elevated maze-plus (EPM) and light-dark box (LDB) $[23,24]$. The compounds effect on mice was spontaneous and tested by locomotor activity test. At higher doses, the mice demonstrated more number of entries and additional time was spent on the open arms of EPM [25]. The transitions occurred have also increased, and similarly, more time was spent in light compartment of the LBD. Treatment with flumazenil significantly reduces anxiolytic-like effects, but treatment with $V$. jatamansi did not affect the spontaneous activity in mice. The study concludes that the compound V.jatamansi can be a better choice for anxiolytic action than producing sedation [26,27].

In another study, the anxiolytic activity was performed using iridoid fraction which was obtained from rhizomes and radix of V.jatamansi using D-101 resin. The major constituents were analyzed preliminarily by TLC, UV spectrophotometry, and HPLC, and its antianxiety effects at $6 \mathrm{mg} / \mathrm{kg}$, $9 \mathrm{mg} / \mathrm{kg}$, and $12 \mathrm{mg} / \mathrm{kg}$ were evaluated using elevated plus maze technique, the Vogel's drinking conflict technique, the open field drink technique, and the LDB technique. The mechanism of action was investigated using ELISA technique and it was shown by regulating GABA level [28].

\section{Neuroprotective effect}

Neuroprotective activity of methanolic extract of the dried roots of $V$. jatamansi was explored using three new iridoids, valeriandoids 


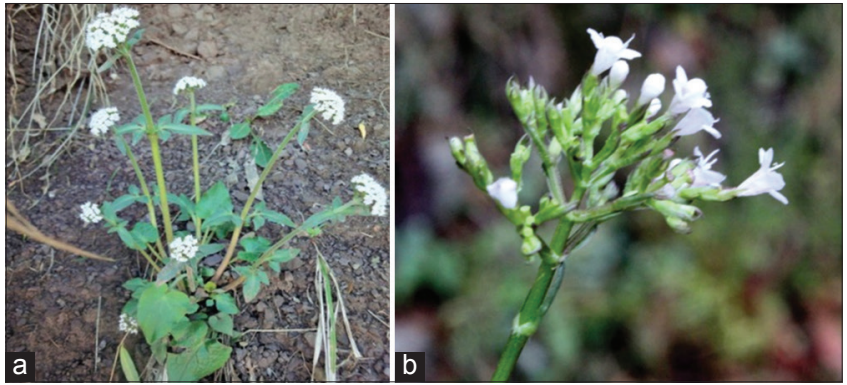

Fig. 1: Morphology of Valeriana Jatamansi, (a) whole plant, (b) flower at early stage [5]

A-C(1-3), and other three already reported compounds (4-6) were subjected against (MPP+) 1-methyl-4-phenylpyridinium-induced neuronal apoptosis in the neuroblastoma of dopaminergic SH-SY5Y utilizing guanosine as positive control. Among these six compounds, four had showed moderate neuroprotective effect (Fig. 1) [8,29].

\section{CONCLUSION}

V. jatamansi is a perennial herb grown in higher altitude regions of Himalayas is an important ayurvedic plant with multiple remedies. The roots and rhizomes of the plant had substantial number of chemical constituents such as iridoids, liganoids, valeriandoids, and valepotriates which are used to treat various ailments. Pharmacologically, it has been evaluated for in vitro antimicrobial, antioxidant, and anticancer activity and in vivo anti-inflammatory, anxiolytic, and neuroprotective activity [30]. However, continuous research on this plant is needed to know the exact molecular mechanism, and further, elaborative studies can lead to develop safe therapeutic use in modern medicine.

\section{ACKNOWLEDGMENT}

The authors are thankful to the School of Pharmaceutical Sciences, Vels Institute of Science, Technology and Advanced Studies, and its management for providing research facilities and encouragement.

\section{REFERENCES}

1. Bhattacharjee SK. Handbook of Aromatic Plants. Jaipur: Pointer Publishers; 2000. p. 458-9.

2. Prakash V. Indian Valerianaceae: A Monograph on Medicinally Important Family. Jodhpur, India: Scientific Publishers; 1999. p. 1-2.

3. Rani S, Sharma TR, Kapila R, Chahota RK. Identification of new cytotypes of Valeriana jatamansi Jones, 1970 (Valerianaceae) from North-Western Himalayan region of India. Comp Cytogenet 2015;9:499-512.

4. Raina AP, Negi KS. Essential Oil Composition of Valeriana jatamansi Jones from Himalayan Regions of India. Indian J Pharm Sci $2015 ; 77: 218-22$

5. Valerianajatamansi, Valerian (Herb). Wikipedia, the Free Encyclopedia. Available from: https://www.en.wikipedia.org/wiki/Valerian(herb).

6. Ying ZH, Ying FA, Zhan-Feng GO, Xue-Yun DU, Yan-Wen LI. Two new terpenoids from Valeriana officinalis. Chin J Nat Med 2009;7:270-3

7. Wills RB, Shohet D. Changes in valerenic acids content of valerian root (Valeriana officinalis L. SL.) during long-term storage. Food Chem 2009;115:250-3.

8. Xu J, Zhao P, Guo Y, Xie C, Jin DQ, Ma Y, et al. Iridoids from the roots of Valeriana jatamansi and their neuroprotective effects. Fitoterapia 2011;82:1133-6

9. Liu YH, Wu PQ, Hu QL, Pei YJ, Qi FM, Zhang ZX, et al. Cytotoxic and antibacterial activities of iridoids and sesquiterpenoids from Valeriana jatamansi. Fitoterapia 2017;123:73-8.

10. Nandhini S, Narayanan KB, Ilango K. Valeriana officinalis: A review of its traditional uses, phytochemistry and pharmacology. Asian J Pharm Clin Res 2018;11:36-41.

11. Sudati JH, Fachinetto R, Pereira RP, Boligon AA, Athayde ML, Soares FA, et al. In vitro antioxidant activity of Valeriana officinalis against different neurotoxic agents. Neurochem Res 2009;34:1372-9.

12. Rao SN, Mittal S, Menghani E. Evaluation of antioxidant properties of Valeriana Wallichi to scavenge free radicals. Asian J Pharm Clin Res 2012;5:238-40.

13. Thusoo S, Gupta S, Sudan R, Kour J, Bhagat S, Hussain R, et al. Antioxidant activity of essential oil and extracts of Valeriana jatamansi roots. Biomed Res Int 2014;2014:4.

14. Kour M, Singh H, Kaur J. In vitro antioxidant and anti-inflammatory activities of hydro alcoholic extract of leaves of Valeriana jatamansi. Int Arch Integr Med 2014;1:18-26.

15. Subhan F, Karim N, Ibrar M. Anti-inflammatory activity of methanolic and aqueous extracts of Valeriana wallichii Dc rhizome. Pak J Plant Sci 2007; 13:103-8.

16. Harsha NM, Dulloo P, Dulloo P. Isolation and identification of antimicrobial proteins from the leaves of Valeriana hardwickii and Senna obtusifolia. Asian J Pharm Clin Res 2018;11:438-40.

17. Habib B, Habeeb MA. Antibacterial activity of Valeriana jatamansi against extended-spectrum $\beta$-lactamase producing Gram negative bacteria causing urinary tract infections. J Coastal Life Med 2016;10:791-4.

18. Babu P, Verma SK, Mathur A. Screening of solvent extracts of Valeriana jatamansi for isolation of antimicrobial compound. Int J Pharm Sci Res 2015;6:2641-8.

19. Awasare S, Bhujbal S, Nanda R. In Vitro cytotoxic activity of novel oleanane type of triterpenoid saponin from stem bark of Manilkara zapota linn. Asian J Pharm Clin Res 2012;5:183-8.

20. Bos R, Hendriks H, Scheffer JJ, Woerdenbag HJ. Cytotoxic potential of valerian constituents and valerian tinctures. Phytomedicine 1998;5:219-25.

21. Lin S, Fu P, Chen T, Ye J, Yang XW, Zhang WD, et al. Three minor valepotriate isomers from Valeriana jatamansi and their cytotoxicity. J Asian Nat Prod Res 2017;19:15-21.

22. Lin S, Fu P, Chen T, Ye J, Su YQ, Yang XW, et al. Minor valepotriates from Valeriana jatamansi and their cytotoxicity against metastatic prostate cancer cells. Planta Med 2015;81:56-61.

23. Sabu NS, Jayachandran TP, Ganesan PS. Evaluation of anxiolytic activity of aerial parts of Sarcostigma kleinii wight and arn. Asian J Pharm Clin Res 2015;8:412-6.

24. You JS, Peng M, Shi JL, Zheng HZ, Liu Y, Zhao BS, et al. Evaluation of anxiolytic activity of compound Valeriana jatamansi jones in mice. BMC Complement Altern Med 2012;12:223

25. Murphy K, Kubin ZJ, Shepherd JN, Ettinger RH. Valeriana officinalis root extracts have potent anxiolytic effects in laboratory rats. Phytomedicine 2010;17:674-8.

26. Benke D, Barberis A, Kopp S, Altmann KH, Schubiger M, Vogt KE, et al. GABA A receptors as in vivo substrate for the anxiolytic action of valerenic acid, a major constituent of valerian root extracts. Neuropharmacology 2009;56:174-81.

27. Zhang XM, Zhu JL, Sun Y, Dai YL, Chen X, Cao JH, et al. Anxiolytic potency of iridoid fraction extracted from Valeriana jatamansi jones and its mechanism: A preliminary study. Nat Prod Res 2018;32:2071-5.

28. Gränicher F, Christen P, Kamalaprija P, Burger U. An iridoiddiester from Valeriana officinalis var. Sambucifolia hairy roots. Phytochemistry 1995:38:103-5.

29. Hattesohl M, Feistel B, Sievers H, Lehnfeld R, Hegger M, Winterhoff H, et al. Extracts of Valeriana officinalis L. S.l. Show anxiolytic and antidepressant effects but neither sedative nor myorelaxant properties. Phytomedicine 2008;15:2-15.

30. Morazzoni P, Bombardelli E. Valeriana officinalis: Traditional use and recent evaluation of activity. Fitoterapia 1995;66:99-112. 